\title{
Oral peptide delivery: prioritizing the leading technologies
}

\author{
"...we are now in a very interesting phase where several delivery technologies are \\ in advanced clinical trials for oral peptides."
}

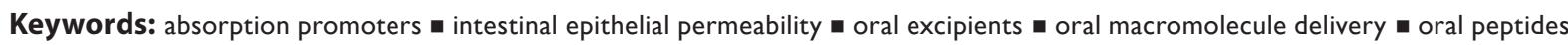

In the late 1980s and early 1990s, oral delivery technologies for macromolecules, peptides and proteins mushroomed at tremendous rates due to a number of very promising preclinical studies. Interest from pharmaceutical companies in these technologies subsequently fell away from in the late 1990s owing to a series of clinical disappointments as many supposed 'platform technologies' failed for a variety of reasons: very low oral bioavailability, toxicity and lack of study reproducibility. Other factors that were implicated in the demise of these programs included formulation and scale-up issues, which prevented the required translation to man. Many lessons were learnt in this period and we are now in a very interesting phase where several delivery technologies are in advanced clinical trials for oral peptides [1,2] and one has now successfully completed the Phase III trials [201]. From our extensive reading of the literature however, one can really get no sense of which oral delivery technologies have been discontinued. For the ones that are still in play, their current status is difficult to ascertain. Moreover, the shift in the field towards translational success for a few technologies with relatively low-molecular weight payloads is not apparent in recent literature.

Perhaps it is no surprise that there is no transparency for the true status of these programs as most reviews on oral delivery of proteins and peptides are written by academics, individuals who may not be fully au-fait with up-to-date industry knowledge. Academic authors are also typically fixated on the elegant mechanisms and elaborate delivery strategies that can be examined using in vitro systems commonly found in university laboratories. Such efforts frequently fail to make the important distinction between systems in the preclinical phase and progression to human trials, a parameter critical for value and investment. At the same time, while failed technologies are unlikely to be still trumpeted by their original champions, these technologies may still persist on 'upbeat' company websites and are, therefore, continually evaluated by successive literature reviews, despite fossilization. The current authors have therefore pooled their knowledge of current projects in an attempt to provide an accurate overview that hopefully provides a realistic perspective of what can be achieved for some of the current best bets in oral peptide and protein-delivery technologies.

In the broader scheme, these delivery technologies can be considered primarily for molecules that fall into the biopharmaceutical classification system describing class III molecules. Commercially relevant peptides in this class include: insulin, glucagon-like-peptide 1 analogues, salmon calcitonin, octreotide, parathyroid hormone and LHRH analogues such as leuprolide. Nonpeptide macromolecules with permeability issues include unfractionated heparin, low-molecular weight heparins, antisense oligonucleotides and vancomycin. One can also consider small molecules such as bisphosphonates, acyline, amphotericin, camptothecin and gentamycin. We apologize in advance for any omissions in this nonexhaustive and personal estimation of the current status of selected technologies for their applications to facilitate the oral delivery of these poorly absorbed, although in most cases reasonably soluble molecules.

\section{Formulations based on oral permeation enhancers}

Permeation enhancers (promoters) directly promote transport of molecules across the intestinal epithelium in the absence of major effects on their solubility. Enhancers are generally classified as either 'tight-junction (TJ) selective' in order

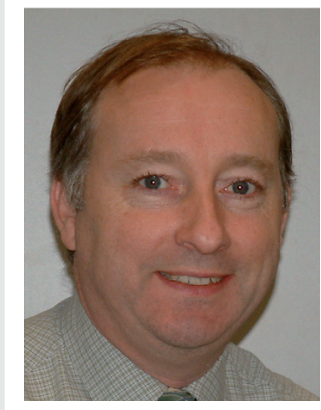

\section{David J Brayden}

Author for correspondence: UCD School of Veterinary Medicine and Conway Institute, University College Dublin, Belfield, Dublin 4, Ireland

Tel.: +353 17166013

Fax: +35317166219

E-mail: david.brayden@ucd.ie

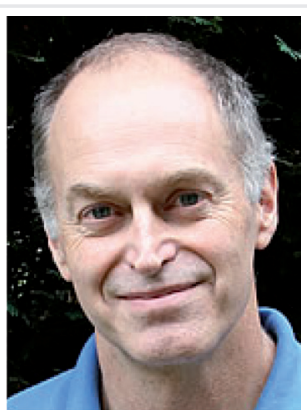

Randall J Mrsny

Department of Pharmacy and Pharmacology, University of Bath, UK 
to increase paracellular permeability through modification of TJ functional properties, or 'membrane perturbing' in order to increase transcellular permeation [3], mechanisms typically ascertained using human Caco-2 epithelial cell monolayers at the maximum concentrations this delicate system can tolerate in vitro. There was some consensus in the early 1990s that the smarter approach for safely delivering poorly permeable molecules was to opt for specific agents that opened $T J s$, since the latter approach of membrane perturbation was considered potentially toxic.

There were several problems with this interpretation, however, and it has gradually been challenged using data achieved with less reductionist methodologies in the intervening period. First, in vivo studies revealed that the concentrations of fatty-acid based enhancers required to promote intestinal absorption far exceeded those used in Caco-2 monolayers and in intestinal tissue mounted in Using chambers [4]; this meant that it was unlikely that specific effects on paracellular barrier properties controlled by TJs could occur in isolation from membrane perturbation effects in vivo. This is the case for the medium-to-long-chain fatty acid-based technologies: for example, C10 in matrix tablets [1], acyl carnitines and bile salts with citric acid [5] and a C8 suspension in a hydrophobic media [101]. These are all now in clinical trials and have a long history of safe use in man. It is likely that these agents act predominantly as mild non-ionic surfactants, ironically quite similar to several approved excipients in oral products. Indeed, Emisphere Technologies (USA) recently achieved 'generally recognized as safe' status for their noncovalent enhancer, sodium 8-([2-hydroxybenzoyl] amino)octanoate for intended use in combination with nutrients added to food and dietary supplements [6]. Second, the thesis that specific TJ-opening peptide-based technologies can induce satisfactory oral bioavailability in vivo has, to date, not been born out. Thus, we await convincing preclinical data to demonstrate the clinical utility of the zonula occludens toxin [7], its mimetic derivatives [8], Clostridium perfingins enterotoxin peptide [9] and melittin [10]. Stability, potency, toxicity and small intestinal apical-receptor expression (in the case of zonula occludens toxin) may all be limiting features, but a conclusion that must be considered at this stage is that specific TJ opening in the absence of membrane perturbation may simply not be enough to achieve significant peptide bioavailability. To our knowledge, no peptide-based enhancer or analogue, or mimetic thereof, specifically targeting the small intestinal TJ is currently being pursued in a clinical strategy for oral peptide delivery. Neither are we aware of current significant interests by pharmaceutical companies in motifs that target specific loops in the TJ protein components occludin [11] or selected claudin proteins [12], although the mechanistic information on TJ regulation that these academic studies provide is fascinating.

Since the most advanced enhancers appear to work via relatively nonspecific mechanisms on both TJs and the transcellular pathway, there is a widely held misconception that they must be toxic. Such a view is not necessarily supported by data, although intuition would suggest that they must be so based upon perceptions from earlier studies with surfactants that overtly damaged intestinal epithelia [13] and, thus, opened both routes via frank lesions. Therefore, it is important to point out that those examples of technologies in the clinic cited above (and in detail in TABLE I) have reported no significant toxicity following administration to several hundred subjects, some on a repeat-dosing basis.

Why might these mild ionic and non-ionic surfactants be safe? We and others have tested the hypothesis that C10-like surfactants work in a unique way that requires formulation with their cargo so that there is co-release in high concentrations close to the intestinal wall [14,15]. This window of increased permeation means that pathogenic bystanders need to be in the immediate vicinity to be co-absorbed. Even assuming that this might actually occur, experience with these enhancers suggests that their efficacy is generally limited to molecules less than $10 \mathrm{kDa}$ in molecular weight, a far cry from preliminary research in the 1990s that 'platform technologies' might orally deliver much larger molecules such as erythropoietin and G-CSF [16]. The upshot of a more realistic assessment of the potential of the advanced enhancers is that pathogenic materials, such as toxins, bacterial lipopolysaccharides and viruses, are outside the limits of either the molecular weight or radii cut-off associated with molecules whose uptake can be enhanced by these agents. Finally, there have been many attempts to model co-absorption of pathogens with enhancers and we are aware of only one 'positive' in vitro study in which monolayers of pulmonary epithelial cultures exposed to apical concentrations of C10-enabled paracellular transport of 
Table 1. Oral permeation enhancers actively being evaluated in advanced clinical trials to enhance peptide delivery.

\begin{tabular}{|c|c|c|c|c|}
\hline Enhancer & Technology & Phase & Company & Ref. \\
\hline $\begin{array}{l}\text { Citric acid } \pm \text { acyl } \\
\text { carnitine }\end{array}$ & $\begin{array}{l}\text { Citric acid in vesicles in a } \\
\text { pH-dependent coated } \\
\text { dosage form; carnitines } \\
\text { used in parathyroid } \\
\text { hormone studies }\end{array}$ & $\begin{array}{l}2011 \text { Phase III } \\
\text { completed for } \\
\text { salmon calcitonin } \\
\text { (reached primary } \\
\text { end point) }\end{array}$ & $\begin{array}{l}\text { Unigene/Tarsa } \\
\text { (USA) }\end{array}$ & [201] \\
\hline $\begin{array}{l}\text { Eligen }^{\circledR} \text { (e.g., } \\
\text { salcaprozate sodium) }\end{array}$ & $\begin{array}{l}\text { Noncovalent interaction } \\
\text { with peptide; non-ionic } \\
\text { surfactant permeation } \\
\text { enhancer }\end{array}$ & $\begin{array}{l}2011 \text { Phase III for } \\
\text { SCT (second of two } \\
\text { studies for } \\
\text { osteoarthritis failed); } \\
\text { Phase III study for } \\
\text { osteoporosis } \\
\text { completed (2011) }\end{array}$ & $\begin{array}{l}\text { Emisphere } \\
\text { Technologies } \\
\text { (USA) }\end{array}$ & [203] \\
\hline Sodium caprate (C10) & $\begin{array}{l}\text { Tablet with alkylated } \\
\text { polyethylene } \\
\text { glycol-peptide conjugate } \\
\text { with permeation enhancer }\end{array}$ & $\begin{array}{l}2011 \text { Phase III } \\
\text { completed for } \\
\text { insulin (failed); new } \\
\text { partner announced. }\end{array}$ & Biocon (India) & [202] \\
\hline Sodium caprate (C10) & $\begin{array}{l}\text { Matrix tablet of } \\
\text { permeation enhancer with } \\
\text { payload }\end{array}$ & $\begin{array}{l}2010 \text { Phase I for } \\
\text { insulin and GLP-1 } \\
\text { analogues (ongoing) }\end{array}$ & $\begin{array}{l}\text { Merrion Pharma } \\
\text { (Ireland) with } \\
\text { Novo-Nordisk } \\
\text { (Denmark) }\end{array}$ & [204] \\
\hline Sodium caprylate (C8) & $\begin{array}{l}\text { C8 permeation-enhancer } \\
\text { suspension in hydrophobic } \\
\text { oil format }\end{array}$ & $\begin{array}{l}2011 \text { Phase I for } \\
\text { octreotide } \\
\text { (completed, Phase III } \\
\text { enrolling) }\end{array}$ & Chiasma (Israel) & [205] \\
\hline
\end{tabular}

an adenovirus [17]. Ironically, medium-chain fatty acids prevent bacterial adherence and are bactericidal in the concentrations used for oral delivery [18].

Of course, potential toxicity after repeat dosing of enhancers is of genuine importance in assessing safety, as is the study of epithelial repair mechanisms in vivo following exposure to such agents. Nonetheless, gaining efficacy and low intra-subject variability in man seems to be of most concern for the oral-delivery companies working at the coalface with surfactant-type enhancers. The nuances of potential toxicity issues seem to have gained higher traction amongst academics, who are likely unaware of the extensive toxicology assessments already undertaken by the oral-delivery companies. In order to stave off full development costs of using a novel enhancer, companies are attracted to established excipients and agents with 'generally recognized as safe' status as they argue for the abbreviated 501(k) regulatory pathway for established agents with good safety credentials from prior use in human products. While some of these may have been adjudged safe by the US FDA for other applications, this does not infer an easier toxicology route through regulatory authorities when these same agents are used in an oral peptide delivery formulation. It is not unreasonable to conclude however, that use of established excipients in oral-delivery systems is likely to load the dice in favor of safer outcomes compared with unanticipated outcomes associated with use of new chemical entities.

\section{Nanoparticulates for oral peptide delivery}

Microparticles, nanoparticles and liposomes of varying construction have been extensively researched for oral peptide-delivery applications. Over the years formulations prepared with polymeric materials including poly(lactide) co-glycolide, chitosans, as well as polymeric cationic lipids with and without polyethylene glycol(PEG)-ylation have been tested. Some materials have even incorporated targeting motifs into these particles. While some of these materials show promising in vitro outcomes, they do not work very well in vivo. There are probably many obscure reasons for this lack of in vivo success, but a few are clear: these materials have been shown to provide poor loading efficiency for the delivered bioactive, they are difficult to synthesize consistently, particularly when scale-up is required, and there is not much evidence of significant intestinal particle uptake by enterocytes. At one point, the advent of stable liposomes ('Orasomes ${ }^{\mathrm{TM}}$ ) [19], suggested 
that entrapped peptides could be delivered orally. This program has since been discontinued; attempts to use Orasomes for oral vaccination by promoting M-cell uptake at Peyer's patches ultimately also proved no more fruitful [20]. Similarly, peptide-loaded chitosan-based nanoparticles still do not appear to be close to the clinical testing and initial efficacy seen in rats [21] has not yet been built upon. The most active off-shoot of particle technologies using chitosans seems to be as adjuvants in nasal vaccination [22]. Oral poly(lactide)co-glycolide microparticles containing peptides or genes went the same way, confounded by instability issues for inefficiently loaded peptides. Furthermore, there is little evidence of successful translation for this technology in oral mucosal vaccination [23], despite vast literature demonstrating M-cell uptake [24]. In addition, technology built around poly-anhydride-based bioadhesive polymers for oral peptide delivery [25] did not translate beyond rodents and dogs despite 15 years of research effort.

Several interesting oral-peptide delivery technologies are currently being examined by academic groups. These include coupling dendrimers to impermeable cargoes [26], amphiphilic polymeric-peptide complexes [27], peptides in water-in-oil and water-in-oil-in water emulsions and in aqueous core nanocapsules [28]. While transport across Caco-2 monolayers continue to be the initial assessment method for new technologies, history has clearly shown that in vitro mechanisms defined in this system fail to provide a complete and realistic picture for in vivo performance. It is important to point out that in vitro studies to examine particulates that facilitate transepithelial transport of poorly absorbed drugs across Caco-2 monolayers do not take into account physiological and physicochemical issues that can affect performance of these materials in vivo. In this regard, there is interesting research investigating how smallchain PEG-poly(sebacic) acid co-polymer coatings may assist particulate movement through mucus [29], a significant in vivo barrier not provided by the Caco-2 monolayer model. Use of this approach may also assist particulate transfer through the viscous airway mucus of cystic fibrosis patients.

Targeting apical membrane receptors Intuitively, the rationale for attaching receptortargeting ligands or cell-penetrating peptides to peptide-loaded particles to boost oral delivery is highly attractive. There is elegance in attempting to use ligands for well-expressed receptors that are internalized at the apical surface of small intestinal cells. To date, such studies have described ligands that target receptors that include the hPEPT1, FcRn, TfnR, hSMVT, cubulin, ICAM-1 or CD54, LRP1 or CD91, and the ganglioside GM1. Peptide mimetics have also been derived from phage display and grafted to particles to increase permeation across the follicular-associated intestinal epithelium [30]. Similarly, conjugates containing oligomeric Tfn coupled to insulin for oral delivery have been described elsewhere [31]. The problem is that, while demonstration of targeting by such particles can be achieved using Caco- 2 monolayers in vitro, overcoming issues related to consistently preparing biocompatible particles with appreciable drug loading and a sufficient number of targeting motifs per particle as well as providing some method for assuring reasonable stability of these materials in the GI tract has proved elusive. Indeed, efforts to use FcRn as a transport receptor in the intestine were thwarted by the intense protease burden that damaged Fc-biotherapeutic chimeras competed for receptor binding with endogenous antibodies. This approach is now progressing better in the less hostile environs of the lung [32]. Difficulties of consistently preparing such complex formulations are amplified when one attempts to translate bench-scale production to that required for pharmaceutical development. To our knowledge, only vitamin $\mathrm{B}_{12}$ is currently being researched as a targeting agent in a biotechnology company, but its progress is constrained by limited overall levels and intrasubject variability of receptor (cubilin) expression, inadequate peptide protection, insufficient vitamin $\mathrm{B}_{12}$ attachment per particle and lack of genuine proof that the uptake is actually mediated by the receptor in vivo [33].

Philosophically, there are two schools of thought as to the relevance of using particles to facilitate oral delivery. One view is that the role of the particle is simply to protect and deposit the peptide or protein therapeutic near the apical epithelial surface at sufficiently high concentrations so that even low permeability (perhaps improved with an enhancer) will suffice. Others argue that actual particle uptake is essential and that targeting performs an essential function in that process. An area where most agree is that peptide- or protein-loaded nano- or microparticles entrapped in a capsule that is stable 
at low $\mathrm{pH}$ is critical to get these labile materials through the destructive environment of the stomach. Without this protection, biologically active protein or peptide therapeutics will not reach the jejunum and/or ileum where the less acidic $\mathrm{pH}$ and lowered enzymatic burden offer a greater probability of successful uptake across the intestinal mucosa.

\section{PEG \& peptide conjugates}

In theory, a highly attractive approach is to conjugate peptides to low-molecular weight PEGs for oral delivery in order to provide metabolic stability in an amphiphilic format via these additional alkyl groups. This is the basis of the technology from Biocon (India), which built upon IP obtained through its takeover of the Nobex Corporation. While the oral insulin (IN-105) conjugate tablet, recently tested by Biocon in a Phase III study, unfortunately failed to meet efficacy end points, safety issues were not apparent [202]. Recent data revealed that C10 is also present in the tablet [34], a switch in enhancer from the original conjugate at Nobex, which used the bile salt sodium cholate [35]. Data obtained using small site-specific PEG conjugates of salmon calcitonin have suggested marginally increased pharmacodynamics in rat intraduodenal instillations [36]. The overall picture from these studies suggests that peptide conjugation to a PEG construct alone is insufficient; formulation optimized with an enhancer will be required to promote absorption of the protected peptide.

\section{Conclusion}

Of all the technologies that have been researched for oral delivery of therapeutic peptides and proteins, rather simple formulations based on mild non-ionic surfactant-like permeation enhancers are by far the most advanced. The permeation enhancers used in these approaches have proved to be clinically safe and are able to achieve fairly consistent, single-digit levels of bioavailability for peptides of $<10 \mathrm{kDa}$. For years these enhancers were viewed as an 'ugly child' of efforts to enhance the oral uptake. Why is this? One reason is that their mechanism of action remains uncertain. In vitro studies have suggested selective and specific mechanisms, but these hypotheses have not been validated in vivo. Unlike other technologies that have addressed the problem by a rational approach, mild ionic and non-ionic surfactant-like permeation enhancers were identified serendipitously. Lacking a clear mechanism of action, preparation of proper dosage forms during the translation to clinical testing has been complicated and it was unclear where to start to identify a compound-related safety signal. These aspects have made these molecules less than attractive to academic research scientists, who prefer to get funding for hypothesis-driven studies, as well as to pharmaceutical development scientists, who are looking for ways to astutely navigate the regulatory route.

Realistic expectations of achievable bioavailability outcomes along with a more measured view of toxicity potential has allowed maturation of technologies being developed by Tarsa, Emisphere, Merrion, Chiasma and others. Even peptide-conjugate technologies built around amphiphilic PEG conjugation seem to require the boost of enhancer co-administration to increase oral bioavailability to appreciable levels. Further research in modifying the chemistry of such enhancers may improve efficacy and could ultimately be worth the full toxicology package that would likely be required. Polymeric nanoparticles, micelles and nanocapsules are yet to deliver on their initial promise, while targeted particles continue to frustrate. Very specific peptide-based technologies targeted to TJ proteins or to pathogen receptors on the apical membrane are yet to make significant clinical impact. Thus, it is the relatively nonspecific enhancers/surfactants (from a mechanistic standpoint) that can be successfully manufactured with peptide payloads in optimized formats, (including simple $\mathrm{pH}$ dependent capsules, water-in-oil suspensions and matrix tablets), that have made the most clinical progress. We wait to see if the elegant particle and specific targeting approaches in preclinical research can achieve as much.

Financial \& competing interests disclosure

$R$ Mrsny is the scientific founder of the company Trinity Biosystems, examining CD91-mediated oral delivery and he has also provided scientific guidance to Syntoxin on the development of their technology to target FcRn receptors. Funding for research in D Brayden's laboratory is supported from Science Foundation Ireland SRC/07/B115. A graduate student is currently part-supported by Merrion Pharmaceuticals Ltd in the drug-delivery laboratory of $D$ Brayden. The authors have no other relevant affiliations or financial involvement with any organization or entity with a financial interest in or financial conflict with the subject matter or materials discussed in the manuscript apart from those disclosed.

No writing assistance was utilized in the production of this manuscript. 


\section{References}

1 Walsh E, Maher S, Adamczyk B et al. Oral delivery of macromolecules: rationale underpinning Gastrointestinal Permeation Enhancement Technology (GIPET $\left.{ }^{\circledR}\right)$. Therapeutic Delivery 2(12), 1595-1610 (2011).

2 Aungst BJ. Absorption enhancers: applications and advances. AAPS J. (2011) (In Press).

3 Aungst BJ. Intestinal permeation enhancers. J. Pharm. Sci. 89, 429-442 (2000).

4 Maher S, Leonard TW, Jacobsen J, Brayden DJ. Safety and efficacy of sodium caprate in promoting oral drug absorption: from in vitro to the clinic. Adv. Drug Deliv. Rev. 61, 1427-1449 (2009).

5 Sinko PJ, Lee YH, Makhey V et al. Biopharmaceutical approaches for developing and assessing oral peptide delivery strategies and systems: in vitro permeability and in vivo oral absorption of salmon calcitonin (sCT). Pharm. Res. 16, 527-533 (1999).

6 Riley MG, Castelli MC, Paehler EA. Sub-chronic oral toxicity of salcaprozate sodium (SNAC) in Sprague-Dawley and Wistar rats. Int. J. Toxicol. 28(4), 278-293 (2009).

7 Fasano A, Uzzau S. Modulation of intestinal tight junctions by Zonula occludens toxin permits enteral administration of insulin and other macromolecules in an animal model. J. Clin. Invest. 99, 1158-1164 (1997).

8 Goldblum SE, Rai U, Tripathi A et al. The active Zot domain (aa 288-293) increases ZO-1 and myosin $1 \mathrm{C}$ serine/threonine phosphorylation, alters interaction between ZO-1 and its binding partners, and induces tight junction disassembly through proteinase activated receptor 2 activation. FASEB J. 25, 144-1458 (2011).

9 Takahashi A, Kondoh M, Uchida H, Kakamu Y, Hamakubo T, Yagi K. Mutated C-terminal fragments of Clostridium perfringens enterotoxin have increased affinity to claudin- 4 and reversibly modulate tight junctions in vitro. Biochem. Biophys. Res. Commun. 410, 466-470 (2011).

10 Maher S, Wang X, Bzik V, McClean S, Brayden DJ. Evaluation of intestinal absorption and mucosal toxicity using two promoters. II. Rat instillation and perfusion studies. Eur. J. Pharm. Sci. 38(4), 301-311 (2009).

11 Tavelin S, Hashimoto K, Malkinson J, Lazorova L, Toth I, Artursson P. A new principle for tight junction modulation based on occludin peptides. Mol. Pharmacol. 64, 1530-1540 (2003).
12 Mrsny RJ, Brown GT, Gerner-Smidt K et al. A key claudin extracellular loop domain is critical for epithelial barrier integrity. $\mathrm{Am}$. J. Pathol. 172, 905-915 (2008).

13 Swenson ES, Milisen WB, Curatolo W. Intestinal permeability enhancement: efficacy, acute local toxicity, and reversibility. Pharm. Res. 11, 1132-1142 (1994).

14 Wang X, Maher S, Brayden DJ. Restoration of rat colonic epithelium after in situ intestinal instillation of the absorption promoter, sodium caprate. Therapeutic Delivery 1, 65-72 (2010).

15 Baluom M, Friedman M, Assaf P, Haj-Yehia AI, Rubinstein A. Synchronized release of sulpiride and sodium decanoate from HPMC matrices: a rational approach to enhance sulpiride absorption in the rat intestine. Pharm. Res. 17, 1071-1076 (2000).

16 Russell-Jones GJ, Westwood SW, Habberfield AD. Vitamin $B_{12}$ mediated oral delivery systems for granulocyte-colony stimulating factor and erythropoietin. Bioconjug. Chem. 6, 459-465 (1995)

17 Coyne CB, Kelly MM, Boucher RC, Johnson LG. Enhanced epithelial gene transfer by modulation of tight junctions with sodium caprate. Am. J. Respir. Cell Mol. Biol. 23, 602-609 (2000).

18 Cox AB, Rawlinson L, Baird AW, Bzik V, Brayden DJ. In vitro interactions between the oral absorption promoter, sodium caprate (C10) and S. typhimurium in rat intestinal ileal mucosae. Pharm. Res. 25, 114-122 (2008).

19 Okada J, Cohen S, Langer R. In vitro evaluation of polymerized liposomes as an oral drug delivery system. Pharm. Res. 12, 576-582 (1995).

20 Clark A, Blair H, Liang L, Brey R, Brayden DJ, Hirst B. Targeting polymerised liposome vaccine carriers to intestinal $\mathrm{M}$ cells. Vaccine 20, 208-217 (2001).

21 Prego C, García M, Torres D, Alonso MJ. Transmucosal macromolecular drug delivery. J. Control. Release 10, 151-162 (2005).

22 Slütter B, Bal S, Keijzer C et al. Nasal vaccination with $N$-trimethyl chitosan and PLGA based nanoparticles: nanoparticle characteristics determine quality and strength of the antibody response in mice against the encapsulated antigen. Vaccine 28, 6282-6291 (2010)

23 Katz DE, DeLorimier AJ, Wolf MK et al. Oral immunization of adult volunteers with microencapsulated enterotoxigenic Escherichia coli (ETEC) CS6 antigen. Vaccine 21, 341-346 (2003).
24 Garinot M, Fiévez V, Pourcelle V et al. PEGylated PLGA-based nanoparticles targeting $M$ cells for oral vaccination. J. Control. Release 120, 195-204 (2007).

25 Furtado S, Abramson D, Burrill R et al. Oral delivery of insulin loaded poly(fumaric-co-sebacic) anhydride microspheres. Int. J. Pharm. 347, 149-155 (2008).

26 Goldberg DS, Vijayalakshmi N, Swaan PW, Ghandehari H. G3.5 PAMAM dendrimers enhance transepithelial transport of SN38 while minimizing gastrointestinal toxicity. J. Control. Release 150, 318-325 (2011).

27 Thompson C, Cheng WP, Gadad P et al. Uptake and transport of novel amphiphilic polyelectrolyte-insulin nanocomplexes by Caco-2 cells-towards oral insulin. Pharm. Res. 28, 886-896 (2011).

28 Vrignaud S, Benoit JP, Saulnier P. Strategies for the nanoencapsulation of hydrophilic molecules in polymer-based nanoparticles. Biomaterials 32(33), 8593-8604 (2011).

29 Tang BC, Dawson M, Lai SK et al. Biodegradable polymer nanoparticles that rapidly penetrate the human mucus barrier. Proc. Natl Acad. Sci. USA 106, 1926819273 (2009).

30 Fievez V, Plapied L, Plaideau C et al. In vitro identification of targeting ligands of human M cells by phage display. Int. J. Pharm. 394, 35-42 (2010).

31 Lim CJ, Shen WC. Comparison of monomeric and oligomeric transferrin as potential carrier in oral delivery of protein drugs. J. Control. Release 106, 273-286 (2005).

32 Bitonti AJ, Dumont JA, Low SC et al. Pulmonary delivery of an erythropoietin FC fusion protein in non-human primates through an immunoglobulin transport pathway. Proc. Natl Acad. Sci. USA 101, 9763-9768 (2004).

33 Clardy SM, Allis DG, Fairchild TJ, Doyle RP. Vitamin $B_{12}$ in drug delivery: breaking through the barriers to a $\mathrm{B}_{12}$ bioconjugate pharmaceutical. Expert Opin. Drug Deliv. 8, 127-140 (2011).

34 Hazra P, Adhikary L, Dave N et al. Development of a process to manufacture PEGylated orally bioavailable insulin. Biotechnol. Prog. 26, 1695-1704 (2010).

35 Iyer H, Khedkar A, Verma M. Oral insulin - a review of current status. Diabetes Obes. Metab. 12, 179-185 (2010).

36 Youn YS, Jung JY, Oh SH, Yoo SD, Lee KC. Improved intestinal delivery of salmon calcitonin by Lys18-amine specific PEGylation: stability, permeability, 
pharmacokinetic behavior and in vivo hypocalcemic efficacy. J. Control. Release 114, 334-342 (2006).

\section{- Patent}

101 Chiasma Therapeutics. WO032140 (2010).

\section{- Websites}

201 Tarsa Therapeutics.

www.tarsatherapeutics.com/News/071211.

html

(Accessed 30 August 2011)
202 Biocon. Biocon announces preliminary data on its novel oral insulin drug candidate. www.biocon.com/biocon_press_release_ details.asp? subLink $=$ news $\&$ Fileid $=408$ (Accessed 30 August 2011)

203 Emisphere Technologies. Emisphere Technologies, Inc. reports notification of first interpretable results on 2nd Phase III study of oral calcitonin in osteoarthritis patients. http://ir.emisphere.com/releasedetail. cfm? ReleaseID $=614932$

(Accessed 25 October 2011)
204 Merrion Pharma. Novo Nordisk starts Phase I trial with oral GLP1 analogue using Merrion Pharmaceutical's GIPET ${ }^{\circledR}$ technology. www.merrionpharma.com/archive/GLP1.pdf (Accessed 30 August 2011)

205 Chiasma Pharma. Chiasma's Octreolin ${ }^{\mathrm{TM}}$ (oral octreotide) shown to inhibit growth hormone in healthy subjects. www.chiasmapharma.com/TickerPage. asp? $\mathrm{id}=1$

(Accessed 30 August 2011) 